\title{
CARBON-FREE GASOLINE ENGINE OPERATION
}

\author{
E. MAGARIL \\ Ural Federal University, Russia.
}

\begin{abstract}
The poor quality of motor fuels in countries with transition economies leads to increased carbon formation in internal combustion engines, and this adversely affects the environmental safety and operational efficiency of vehicles. Carbon deposits increase an engine's requirements for a gasoline octane rating, the specific fuel consumption and emissions of toxic substances in the exhaust gases, while the engine's power is actually reduced. The aim of this work is to substantiate a low-cost method for carbon-free gasoline engine operation, which will guarantee a significant improvement to the environmental and operational characteristics of vehicles. It was shown that the removal of carbon formation is possible by applying to the engine's working surfaces an ultrafine metal catalytic layer that promotes carbon gasification. The method of coating the inner surface of an engine with such a catalytically active metal nanolayer was developed and its formation was confirmed by microscopic examination. The results confirming the high efficiency of this method with respect to the environmental impact and performance of the vehicles are presented.
\end{abstract}

Keywords: Carbon formation, catalysis, catalytically active nanolayer, exhaust gas composition, fuel consumption, gasification.

\section{INTRODUCTION}

The strong influence of carbonization on the operational and environmental characteristics of gasoline engines compels car manufacturers to tighten the requirements for a boiling point of $90 \%$ and a final boiling point of gasoline and content of alkenes and aromatics in it, as is recorded in the Worldwide Fuel Charter [1]. In Russia and other countries with transitional economies, the shortage of high-quality components of motor fuels as a consequence of serious problems in the oil-refining industry leads to an increase in the content of aromatic hydrocarbons in gasoline, causing increased carbonization in engines. A strategic solution to the problem of low-quality motor fuels requires large-scale modernization to the oil-refining industry and high investment and time outlays for its implementation. Meanwhile, carbon deposits increase the dependency on an octane number of the gasoline used by up to 10 points due to the higher temperature in the combustion chamber, which exacerbates the problem of the shortage of high-octane gasoline and increases emissions of oxides of carbon and nitrogen.

In addition, carbon deposits in engines cause surface ignition. As a result of preignition in a compression stroke as well as a significant increase in friction after carbon deposition on the working surfaces of the engine, energy consumption for compressing substantially increases. It results in increased fuel consumption with consequential emission of greenhouse gases $\left(\mathrm{CO}_{2}, \mathrm{CH}_{4}\right.$, etc.), and in reduced engine power. It should also be noted that with the elimination of carbonization, emissions of the carbon deposits' precursors, such as polycyclic aromatic hydrocarbons, including strong carcinogen benzo(a)pyrene, are almost completely eliminated. Previous studies made by the authors [2-7] on the effect of carbon formation on the operational and environmental characteristics of vehicles' engines have reaffirmed the desirability of developing a method to remove carbon deposits in engines. The implementation of carbon-free engine's operation is in the interest of not only countries that have transition economies but also developed countries. 


\section{BACKGROUND TO THE METHOD OF MAINTENANCE OF THE CARBON-FREE ENGINE OPERATION}

Essentially, the prevention of carbonization can be achieved by applying to the working surfaces of the engine a layer of catalytically active metal that is capable of accelerating the rate of reactions of carbon gasification and oxidation:

$$
\begin{gathered}
\mathrm{C}+\mathrm{H}_{2} \mathrm{O} \rightarrow \mathrm{CO}+\mathrm{H}_{2}, \\
\mathrm{C}+\mathrm{CO}_{2} \rightarrow \mathrm{CO}, \\
\mathrm{C}+\mathrm{O}_{2} \rightarrow \mathrm{CO},
\end{gathered}
$$

Taking into account the sharp increase in catalytic activity subsequent to the transition of metals to the nanostructured state as well as the degree of working clearance in the engine, it is efficient to apply the catalytically active metal on the working surfaces in an ultrafine state. A nanolayer of metal that catalyzes the gasification of carbon deposit and gum residues on the inner surfaces of internal combustion engines (ICE) will uniquely change their characteristics. It is known that the transition to the nanoscale state leads to a dramatic change in the physical and chemical properties of substances, especially regarding their reaction activity. This determines the preferred usage of nanostructured and nanoscale materials in the development of a new generation of catalysts. A substantial increase in the proportion of surface atoms relative to their total amount within nanostructured catalysts leads to a rise in the specific activity of the metal by comparison with conventional solid catalysts.

On the basis of analytical studies on the effect of fuel quality on the operational and environmental characteristics of vehicles [2-7] and data on the catalytic and physico-chemical properties of substances [8-10], we have formulated the following required properties for the catalytically active metal that can improve the environmental performance of gasoline engines.

- The metal should be an effective catalyst for the oxidation and gasification of carbon deposits. Carbon elimination and the consequential decrease in the temperature within the combustion chamber of a gasoline engine reduce the engine's requirements for a gasoline octane rating. This reduced peak temperature caused by the elimination of carbon reduces the thermodynamically possible formation of nitrogen and carbon oxides and eliminates surface ignition. The amount of carbon deposit on the walls of the combustion chamber depends on the speed ratio of the reaction of condensation of aromatic and unsaturated hydrocarbons within the wall's boundary film and the reaction of oxidation and gasification of the products of that condensation (and their precursors) by oxygen, water and carbon dioxide.

- The metal should promote the complete oxidation and gasification (under oxygen deficiency conditions) of hydrocarbons and their oxy-derivatives generated in the low-temperature area within the wall's boundary film.

- The catalytic properties of the metal should accelerate the reactions of decomposition and/or reduction of nitrogen oxide and the oxidation of carbon monoxide:

$$
\begin{gathered}
\mathrm{NO} \rightarrow \mathrm{N}_{2}+\mathrm{O}_{2}, \\
\mathrm{NO}+\mathrm{CO} \rightarrow \mathrm{N}_{2}+\mathrm{CO}_{2}, \\
\mathrm{CO}+\mathrm{O}_{2} \rightarrow \mathrm{CO}_{2}
\end{gathered}
$$

- The metal's properties of infusibility and corrosion stability should prevent its removal from the combustion chamber and inhibit corrosion of the wall. Its plasticity will also have a positive influence on the cylinder-piston group. Introduction of the metal in minor amounts should prevent any adverse effects on engine performance. 
We have formulated the requirements for the product on a base of catalytically active metal, the introduction of which will ensure the formation of the metallic nanolayer on the working surfaces of the engine.

- The product should possess high surface activity to reduce surface tension at the boundary of the fuel with air and so improve its dispersion.

- The product should not promote the formation of any toxic substances in the exhaust gases that are not generated when using fuel without it.

- The product must be able to be synthesized from available and cheap raw materials.

On the basis of the formulated requirements and the screening of data on the catalytic properties of substances, as well as data relating to the influence of the highly efficient additives used in micro concentrations on the environmental and operational characteristics of motor fuels [2-7, 11, 12], the author has substantiated the formula for a fuel-soluble metal compound with high surfactant properties and catalytic activity in oxidation-reduction reactions. This compound [RCOO $]_{2} \mathrm{Me}$ (where $\mathrm{R}$ is the alkyl radical) was used as a product suitable for the formation of the catalytically active nanolayer (CAN) on the working surfaces of an engine.

The product of original technology CAN is created by adding to the gasoline precisely controlled microamounts of $[\mathrm{RCOO}]_{2} \mathrm{Me}$ in either a single or repeated applications. The introduction of the compound into the engine as a gasoline additive lowers the surface tension of the fuel at the interface with air, which improves the mixture formation in the engine. This ensures a high level of dispersion of the metal compound in the fuel mixture. The decomposition through combustion of the metallic compound in the gasoline engine and the subsequent deposition of metal ensure CAN formation.

Uniformity of metal distribution in the nanolayer is provided by the fuel mixture conditions in the engine, namely high turbulence, temperature and pressure during the combustion process and the temperatures of the working surfaces that are significantly lower in comparison with the melting point of the catalytically active metal.

\section{MICROSCOPIC STUDIES OF THE CATALYTICALLY ACTIVE NANOLAYER}

Because of the difficulties inherent in simulating the fuel mixture conditions in a real engine using laboratory methods, the experiments on CAN formation were performed in cars of different makes and the CAN formation was confirmed by microscopic examination.

The samples for microscopic examination were prepared from the electrodes of spark plugs (cross section) from a VAZ 2110 vehicle with a VAZ 2111 engine. Among them: sample 1 - a new spark plug; sample 2 - a spark plug after use with a remarkable carbon deposit layer; sample 3 - a spark plug after use identical to the second one but treated with the developed technology one day after CAN formation ( $2 \mathrm{mg}$ of catalytically active metal were introduced once into the engine in the form of the fuel-soluble compound $[\mathrm{RCOO}]_{2} \mathrm{Me}$ ); sample 4 - a spark plug after usage identical to the second one ( $3 \mathrm{mg}$ of catalytically active metal were introduced once into the engine); sample 5 - a spark plug one day after treatment that was counter to the technology (30 mg of catalytically active metal were introduced once into the engine, the concentration of $[\mathrm{RCOO}]_{2} \mathrm{Me}$ was of an order of magnitude higher than the optimal one).

Before study, samples were fixed in special holders and polished to a mirror finish following washing and drying. First, the state of the samples was checked by optic microscope Olympus GX-71 [4]. It was observed that after the introduction of $2 \mathrm{mg}$ of active metal into the engine, carbon deposits decreased significantly with only separate fragments remaining on the surface, whereas the introduction of 
$3 \mathrm{mg}$ of metal led to almost complete elimination of carbon deposition and a visible 'smoothing' of the electrode surface.

The loss of the positive effect by increasing the concentration of metal to a degree significantly over the optimal amount (sample 5) should be attributed, obviously, to the sharp decline in the catalytic activity of the applied coating due to the lower degree of metal dispersion.

Further studies of samples 1-4 were carried out using high-resolution scanning electron microscopy by the scanning electron microscope Quanta-200 equipped with system Pegasus (lateral resolution of $5 \mathrm{~nm}$ ) [13]. Electron microscopic analysis was performed on each sample by taking multiple images periodically in back-scattered secondary electrons using varying degrees of magnification. Typical electron micrographs are shown in Fig. 1a-f. Analysis of the electron micrograph of sample 1 (a new spark plug, Fig. 1a) revealed no specific features on the cross-section with the exception of micro-roughness of the surface (the defects of mechanical treatment). In Fig. 1b, the micrograph of sample 2 is presented. The image of the cross-section is quite different and shows the presence of a thick irregular layer of carbon deposit (from a few up to tens of microns) on the surface of the sample. The internal structure of the deposit is characterized by fragmentation and its surface by pronounced roughness.

Figure 1c and d (sample 3) and e and f (sample 4) shows the typical electron-microscopic images of the surface of the cross-sections after applying the catalytically active metal. Special attention in the analysis was paid to the detailed study of the fine structure of the near-surface layer. In Fig. 1c,the presence of a thin (thickness of 1-2 $\mathrm{mm}$ ) nanostructured near-surface electrode layer is clearly observed. The size of nanofragments varies from 50 to $150 \mathrm{~nm}$ with the predominant size being $<100 \mathrm{~nm}$.

When considering the nature of the observed contrast in the metal nanocrystallites, it should be noted that a relatively weak contrast like 'salt-pepper' is conditioned by the absence of phase and chemical immiscibility. Therefore, it is not universally observed. As is known, the contrast is much sharper (clearer) if alternate nanocrystals have different elemental and phase composition as well as interphase or intergrain boundaries of an incoherent (dislocation) type. The phenomenon of the nanolayer 'healing' the defects of the external electrode surface (Fig. 1c and d) was observed and there were practically no traces of carbon deposit on it (Fig. 1c-f).

It should be noted that the operating clearances between the cylinder and the piston in the engine $(0.1-0.15 \mathrm{~mm})$ and also those between the electrodes of the spark plugs are significantly greater than the thickness of the created nanostructured layer. This eliminates the negative impact of CAN on the engine's performance and the risk of its mechanical removal by friction.

\section{RESULTS OF THE APPLICATION OF THE METHOD FOR MAINTAINING CARBON-FREE ENGINE OPERATION}

The influence of the developed method on specific fuel consumption was studied during road tests using UZ-Daewoo vehicles fitted with Nexia SOHC gasoline engines, which had traveled 20,000 $\mathrm{km}$ before the test. The reduced specific fuel consumption, determined by the difference in consumption of the test and control vehicles relative to the test run, after a single-stage treatment of the test vehicle's engine and the formation of the catalyst nanolayer on the working surfaces was $12.3 \%$. The application of the catalyst nanolayer reduced the requirements of the test vehicle's engine on the octane number of gasoline used by 10 points. Investigation into the influence of our method using the CAN application on carbonization in an engine showed that the catalysis of carbon gasification provides significant cleaning of spark plugs, valves and the cylinder-piston group. Figure 2 shows the photographic evidence of the control and test (coated with a catalytic layer) engines after the test run. 
a)

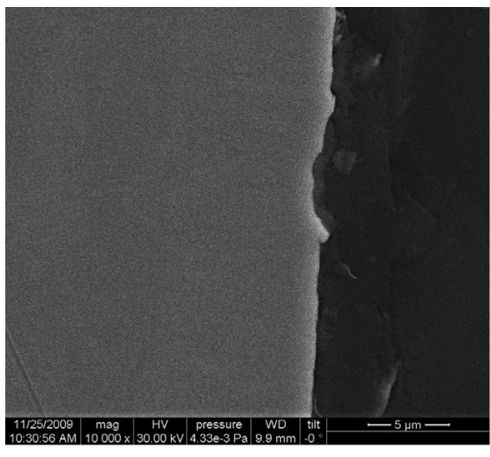

c)

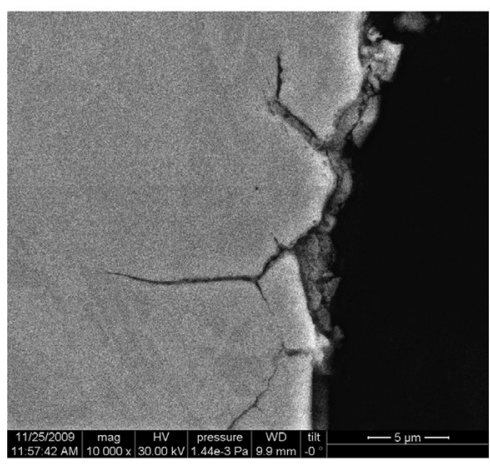

e)

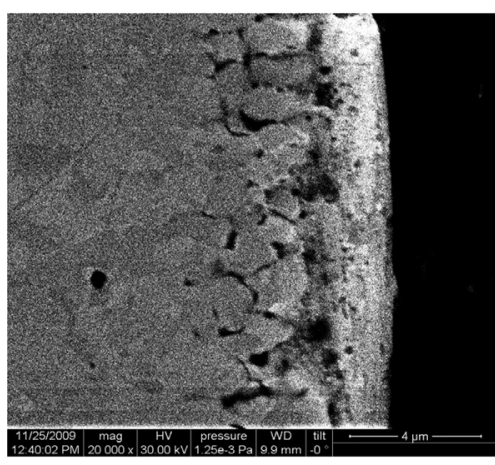

b)

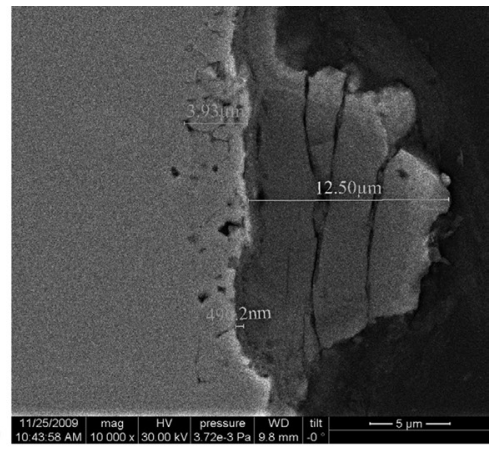

d)
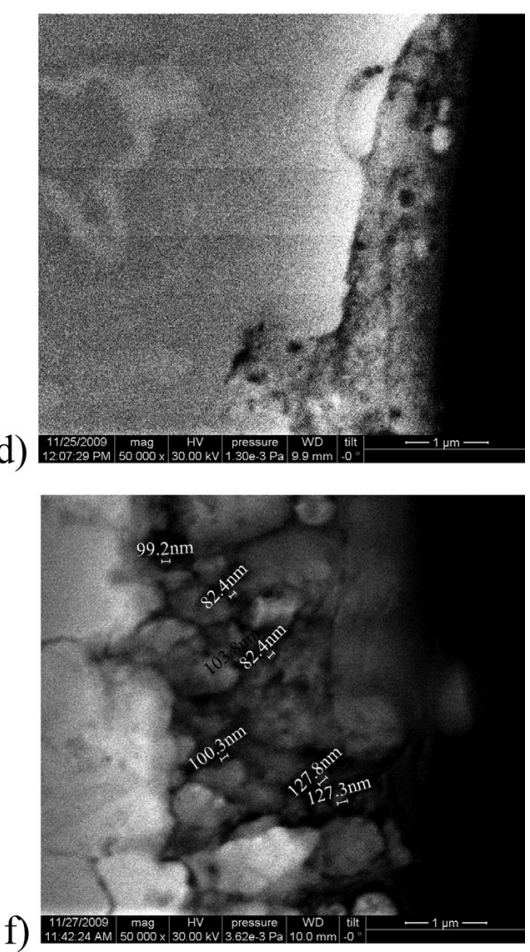

Figure 1: Electron microscopic images of samples in back-scattered secondary electrons (on the left the image of the electrode; on the right - the substance of the holder): (a) sample 1; (b) sample 2; (c and d) - sample 3; and (e) and f) - sample 4.

Atomic absorption analysis revealed that engine exhaust gases contained no metal from the CAN. This fact and the data on the uniform removal of carbon deposits from the engine's working surfaces confirm the very regular formation of the catalytic nanolayer [4].

The dependence of the amount of polycyclic aromatic hydrocarbons in the exhaust gases of the GAZ-3102 when idling and using gasoline with an octane number of 92 (defined by the research method) on the amount of metal introduced into the engine was investigated. Measurement of the concentration of benzo(a)pyrene and other polycyclic aromatic hydrocarbons was carried out by the high performance liquid chromatography (HPLC) method with fluorescence detection utilizing a 


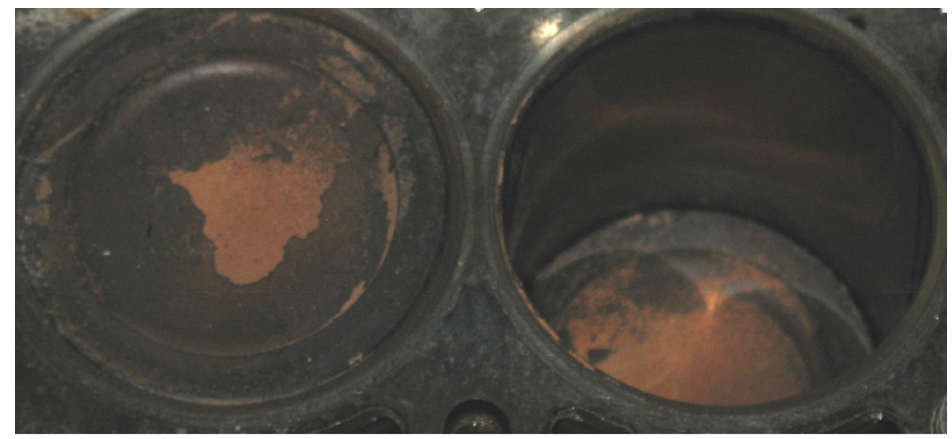

a)

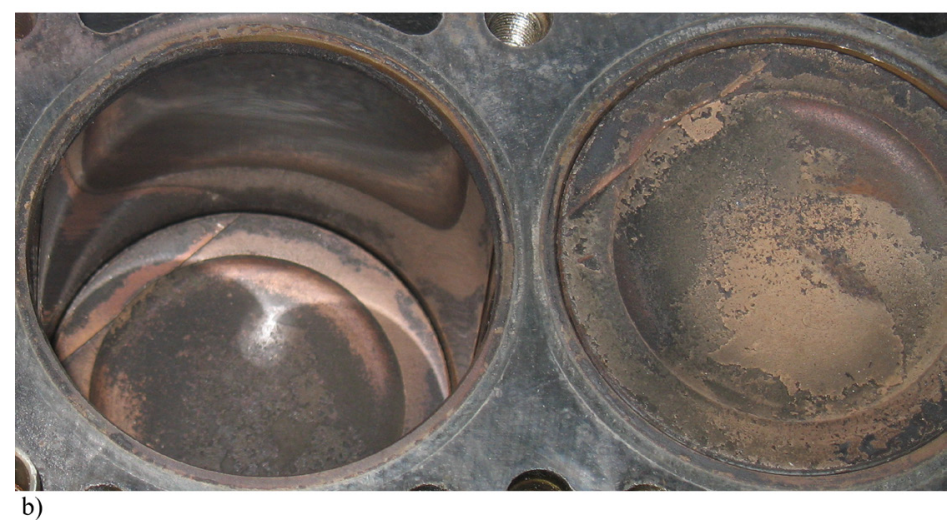

Figure 2: The state of the cylinder-piston group of the Nexia SOHC engines of UZ-Daewoo vehicles after the test run: (a) control vehicle and (b) test vehicle coated with the catalytic layer.

Varian 9075 chromatograph. The concentration of benzo(a)pyrene was determined by the absolute calibration method.

The high efficiency of the developed method (Table 1) in relation to the decrease in emissions of polycyclic aromatic hydrocarbons is associated with the effective catalysis of the gasification reactions by CAN deposited on the engine walls. From the presented results, it is clear that with an introduction into an engine of 3-5 mg of metal in the form of [RCOO $]_{2} \mathrm{Me}$ with gasoline, emissions of benzo(a)pyrene and its analogues reduce by approximately $95 \%$.

It can be assumed that such a positive effect, previously unseen in traditional catalysts based on the metal selected as the influence on emissions of benzo(a)pyrene and its analogues, is related to the determinative role of the nanoscale features of CAN. It can be confirmed by the notable reduction in observed positive effects when an increased concentration of the metal-containing product that is greater than the optimal value (Table 2) is introduced into the fuel. Maximal efficiency in reducing emissions of polycyclic aromatic hydrocarbons is achieved with very low concentrations $[\mathrm{RCOO}]_{2} \mathrm{Me}$ of $0.06-0.10 \mathrm{mg} \mathrm{Me} / \mathrm{kg}$ of gasoline. This effect persists long after the introduction of the metal in the form of a solution $[\mathrm{RCOO}]_{2} \mathrm{Me}$ in gasoline into an engine.

Obviously, by increasing the concentration of the product on a base of metal after its combustion in ICE a thicker layer of metal forms on the working surfaces of the engine. By reducing the degree of its dispersion and with the formation of larger microstructures, the catalytic activity of the deposited metal decreases correspondingly. 
Table 1: The influence of single-stage introduction of $[\mathrm{RCOO}]_{2} \mathrm{Me}$ into the gasoline of a running engine on the presence of benzo(a)pyrene and other polycyclic aromatic hydrocarbons in the exhaust gases.

\begin{tabular}{lcc}
\hline $\begin{array}{l}\text { Amount of the metal } \\
\text { introduced into the } \\
\text { engine }(\mathrm{mg})\end{array}$ & $\begin{array}{c}\text { Total concentration of } \\
\text { polycyclic aromatic } \\
\text { Concentration of } \\
\text { benzo(a)pyrene }\left(\mathrm{mg} / \mathrm{m}^{3}\right)\end{array}$ & $\begin{array}{c}\text { benzo(a)pyrene }\left(\mathrm{mg} / \mathrm{m}^{3 *}\right) \\
\text { benzons, lighter than }\end{array}$ \\
\hline 0 & 0.00023 & 0.00583 \\
2 & 0.000069 & 0.00181 \\
3 & 0.00001 & 0.00030 \\
5 & 0.000009 & 0.00029 \\
35 & 0.00001 & 0.00030 \\
90 & 0.00009 & 0.00230 \\
180 & 0.00018 & 0.00466 \\
\hline
\end{tabular}

*Sensitivity indexes in relation to benzo(a)pyrene are taken as being equal to 1 .

Table 2: Influence of the concentration of $[\mathrm{RCOO}]_{2} \mathrm{Me}$ in the gasoline on the content of benzo(a) pyrene and other polycyclic aromatic hydrocarbons in the exhaust gases.

\begin{tabular}{|c|c|c|}
\hline $\begin{array}{l}\text { Concentration of }[\mathrm{RCOO}]_{2} \mathrm{Me} \\
\text { in the gasoline }(\mathrm{mg} \mathrm{Me} / \mathrm{kg})\end{array}$ & $\begin{array}{c}\text { Concentration of } \\
\text { benzo(a)pyrene }\left(\mathrm{mg} / \mathrm{m}^{3}\right)\end{array}$ & $\begin{array}{l}\text { Total concentration of } \\
\text { polycyclic aromatic } \\
\text { hydrocarbons }\left(\mathrm{mg} / \mathrm{m}^{3 *}\right)\end{array}$ \\
\hline \multicolumn{3}{|c|}{ Total amount of metal introduced into the engine is equal to $3 \mathrm{mg}$} \\
\hline 0 & 0.00023 & 0.00583 \\
\hline 0.06 & 0.000007 & 0.000175 \\
\hline 0.10 & 0.000007 & 0.000175 \\
\hline 0.46 & 0.000009 & 0.00029 \\
\hline 0.925 & 0.00001 & 0.00030 \\
\hline 1.39 & 0.00001 & 0.00030 \\
\hline 1.85 & 0.000009 & 0.00029 \\
\hline 2.78 & 0.00001 & 0.00030 \\
\hline \multicolumn{3}{|c|}{$\begin{array}{c}\text { At } 3 \text { months after the introduction of } 3 \mathrm{mg} \text { of metal into an engine in the form of }[\mathrm{RCOO}]_{2} \mathrm{M} \\
\text { solution in gasoline }\end{array}$} \\
\hline 0.10 & 0.000007 & 0.000175 \\
\hline \multicolumn{3}{|c|}{$\begin{array}{c}\text { At } 6 \text { months after the introduction of } 3 \mathrm{mg} \text { of metal into an engine in the form of }[\mathrm{RCOO}]_{2} \mathrm{M} \\
\text { solution in gasoline }\end{array}$} \\
\hline 0.10 & 0.000007 & 0.000175 \\
\hline \multicolumn{3}{|c|}{$\begin{array}{c}\text { In } 12 \text { months after introduction of } 3 \mathrm{mg} \text { of metal into an engine in the form of [RCOO}]_{2} \mathrm{Me} \\
\text { solution in gasoline }\end{array}$} \\
\hline 0.10 & 0.000007 & 0.000175 \\
\hline
\end{tabular}

*Sensitivity indexes in relation to benzo(a)pyrene are taken as being equal to 1 . 
Table 3: Influence of the developed method on the emission of toxic substances and specific fuel consumption in the combined cycle (ECE-15 + EUDC) $(\alpha \geq 1.02)$.

\begin{tabular}{lccccc}
\hline & \multicolumn{4}{c}{ Emisson $(\mathrm{g} / \mathrm{km})$} & Gasoline consumption \\
\cline { 2 - 5 } Engine & $\mathrm{CO}$ & $\mathrm{CH}$ & $\mathrm{NO}_{\mathrm{x}}$ & $\mathrm{CO}_{2}$ & $(1 / 100 \mathrm{~km})$ \\
\hline Before treatment & 3.3 & 1.6 & 2.0 & 147.1 & 9.62 \\
After the catalytic & 2.3 & 1.3 & 2.0 & 138.4 & 8.95 \\
$\begin{array}{l}\text { nanolayer application } \\
\text { Change }(\%)\end{array}$ & -30.3 & -18.8 & - & -5.9 & -7.0 \\
\hline
\end{tabular}

Tests on the influence of the developed method on the emissions of toxic substances in the exhaust gases were carried out at the roller stand 'Zollner' RPL 510/22CM6.8-23/GPM-100 on a VAZ-2110 vehicle that had traveled $15,000 \mathrm{~km}$ before the test using gasoline with research octane number 92 . Test results are shown in Table 3.

It can be assumed that to a great extent it is the catalytic removal of carbon deposits that gives the observed effects of reduced $\mathrm{CO}$ emission (the result of a lower peak temperature) and a decrease in the specific consumption of gasoline (the result of surface ignition elimination and reduced heating of the fuel-air mixture from the wall). The decrease in gasoline consumption leads to a reduction in $\mathrm{CO}_{2}$ emissions and the catalysis of the gasification reactions reduces hydrocarbon emissions.

It should be noted that with a substantial reduction in $\mathrm{CO}$ emissions after the deposition of the CAN, the emission of nitrogen oxides remains constant. This can be explained by the fact that in tests at $\alpha>1$ the concentration of $\mathrm{CO}$ was low and at the same time the nitrogen oxide emission by catalysis of the reaction $\mathrm{CO}+\mathrm{NO} \rightarrow \mathrm{CO}_{2}+\mathrm{N}_{2}$ decreases only with sufficiently high concentrations of $\mathrm{CO}$. In tests at $\alpha<1$ after the formation of the catalyst layer in the engine, the emission of nitrogen oxides as a result of this reaction decreased by $27 \%$ with constant $\mathrm{CO}$ emission.

Thus, the investigations and tests carried out confirm that the formation of the CAN on the working surfaces of gasoline engines ensures a reduction in emissions of polycyclic aromatic hydrocarbons including benzo(a)pyrene by $95 \%$ and also eliminates carbon deposits. As a result of carbon deposit removal and appropriate mitigation of temperature conditions in the engine, the dependency on a gasoline octane rating reduces by up to 10 points and the specific consumption of fuel decreases by $7-12 \%$. This then leads to reduced emission of greenhouse gases and toxic gaseous substances. The positive effects of the method remain for at least 12 months after a single deposition of CAN within the engine, significantly increasing the efficiency and environmental safety of vehicles with no increase in the cost of engine production because of the very low cost of metal deposition.

\section{CONCLUSIONS}

The method of carbonization removal by depositing on the working surfaces of an engine a CAN that accelerates the reactions of oxidation and gasification of high-molecular polycyclic aromatic hydrocarbons and carbon deposits was developed. This ensures that surfaces within cylinders, pistons and spark plugs of the gasoline ICE remain clean, significantly improving the engine's fuel efficiency and the vehicle's environmental performance.

Maintaining carbon-free operation of vehicles with gasoline engines by applying CAN is an alternative way to solve the problem of the shortage of high-octane gasoline as elimination of carbon deposits reduces an engine's dependency on a gasoline octane rating. Mandatory application of this 
method ensures that within a short time and with minimal investment, significant environmental benefits in urban areas are attained and an essential reduction in gasoline consumption is achieved.

\section{REFERENCES}

[1] Worldwide Fuel Charter, 5th edn, 2012, available at http://www.acea.be/collection/publications.

[2] Magaril, E., Improving car environmental and operational characteristics using a multifunctional fuel additive. WIT Transactions on Ecology and the Environment, 147, pp. 373-384, 2011. doi: http://dx.doi.org/10.2495/air110351

[3] Magaril, E., The influence of carbonization elimination on the environmental safety and efficiency of vehicle operation. International Journal of Sustainable Development and Planning, 8(2), pp. 231-245, 2013. doi: http://dx.doi.org/10.2495/sdp-v8-n2-231-245

[4] Magaril, E., Improving the efficiency and environmental safety of gasoline engine operation. WIT Transactions on Built Environment, 130, pp. 437-445, 2013. doi: http://dx.doi.org/10.2495/ut130341

[5] Magaril, E.R., Influence of the Quality of Engine Fuels on the Operation and Environmental Characteristics of Vehicles: Monograph [in Russian], KDU: Moscow, 2008.

[6] Magaril, E.R. \& Magaril, R.Z., Motor Fuels [in Russian], 2nd edn, KDU: Moscow, 2010.

[7] Magaril, E. \& Magaril, R., Motor Fuels: the Problem of Energy Efficiency and Environmental Safety: Monograph [in Russian], LAP LAMBERT Academic Publishing GmbH\& Co: Saarbrücken, Germany, 2012.

[8] Roiter, V.A. (main editor), Catalytic Properties of Substances [in Russian], Naukova dumka: Kiev, 1968.

[9] Thomas, C., Catalytic Processes and Proven Catalysts, Academic Press: London and New York, 1970. doi: http://dx.doi.org/10.1002/ange.19710832023

[10] Germain, J.E., Catalytic Conversion of Hydrocarbons, Academic Press: London and New York, 1969. doi: http://dx.doi.org/10.1016/0021-9517(69)90441-2

[11] Bowers W.E. et al., Gasoline additives and gasoline containing soluble platinum group metal compounds and use in internal combustion engines, US Patent, 4891050 A, 1986.

[12] Carroll, R.W. et al., Method and composition for improving fuel combustion, WO 03040269 A1, 2003.

[13] Magaril, E.R., Magaril, R.Z., Bamburov, V.G., Pushin, V.G. \& Chendarev, A.V., Protective catalytic nanolayer for the gasoline internal combustion engines [in Russian]. Chemical Engineering, 12(8), pp. 485-490, 2011. 